\title{
Biomechanical analysis of bilateral deficit phenomenon for upper limbs in Weight training \\ *Dr/ Hani Abdol Aziz Saleh
}

\section{Introduction:}

Garykamen, Gordon E, Rbertson, Graham E, Caldwell, Joseph Hamill, and Saunders N, Whittlesey (2004) see it as the duty of sport-related science to come up with the latest methods that can be used. To analyze and study sports movement, in order to determine the best form of performance can be performed in order to develop and improve the level of sports performance. (4:1)

Ehab Abdel-Basir and Adel Abdel-Basir (2005) report that each part of the chain is equipped with a driving force, which is the strength of the muscles that can be fixed at the same time, thus changing the parts of the chain, thus changing the degree of freedom of movement. (2: 110 - 109) Hani Abdulaziz (2019) also emphasizes that dynamic motor performance requires many special skills and each skill includes a set of performance and that the most effective way to improve and develop performance is kinetic analysis, where it requires determining the correct mechanical performance of the skill. (7:34)
The phenomenon of bilateral disability is one of the mathematical phenomena that have been studied from the perspectives of science related to sports for the purpose of interpretation. :

\section{Reaction Time Deficit.}

Mahmoud Qasim Ali (2009), citing Ohtsuki (1981), suggests that the deficiencies in the reaction time of the lower body can be explained by the fact that binary motion forces the activation of both hemispheres of the brain, whereas unilateral motion essentially requires a single hemisphere. The stimulus does not affect, he concludes, that bilateral delays in the reaction time of the upper body can be due to the fixation of the inner lobe of the brain that analyzes information and decisionmaking and that during the performance of bilateral action (BL) the central nervous system becomes interested not only in the reactionary task In hand but also in conjunction and coordinate movement of the parties This dispersion of the overall performance. (14: 7), (19:8)

Aerobic performance deficits

* Assistant Professor in Sports Training and Movement Science Department, Faculty of Physical Education for (Men - Girls) in Port-Said, Port-Said University

Associate professor at Faculty of education - Physical Education \& Movement Science Department, Al Qassem University, K.S.A

Assiut Journal For Sport Science Arts 
Glacier Ohtsuki (1981) points out that there is a decrease in the maximum volume of oxygen consumption when performing bilateral versus individual training, where the maximum volume of oxygen consumption during cycling with men was $23 \%$ greater than the maximum volume of oxygen consumption during cycling with one man. It is assumed that the maximum oxygen consumption is linked to muscular work, doubling the muscle size will lead to a doubling of the maximum volume of oxygen consumption, but this hypothesis has not been achieved, which indicates the existence of bilateral deficit. (19: 4)

\section{Muscle Power Deficit}

Glacier Ohtsuki (1981), in their choice of t-leg force during Bilateral BL, and UL (Unilateral), indicates that the force during tethering of the legs together (BL) is approximately $75 \%$ of the average total force produced during an intramuscular accident. In UL, the decrease in BL deficit reached 13: $25 \%$ and the reason for this deficit was explained by the incomplete motor unit (MU) activity in the muscle when both parties worked together. (19: 8)

\section{Research importance and} problem:

Through the researcher readings in the phenomenon of bilateral disability, and where addressed from more than a scientific point of view, the researcher has concluded to three possible causes of the phenomenon of secondary disability are either due to deficit or lack of reaction time, or deficit oxygen performance, or because of muscle power deficit. (14: 8)

However, to the knowledge of the researcher did not address the researchers to the mechanical causes of the phenomenon of bilateral disability and the contribution of biomechanics to the interpretation of this phenomenon.

The researcher believes that the performance angles may have an effect in the interpretation of the phenomenon of bilateral disability, so the researcher tried to explain the phenomenon of bilateral disability through biomechanical analysis, which may explain the existence of this phenomenon in athletes, which serves both theoretical and practical in training in various individual and collective sports.

\section{Research Goals:}

This study aim disability of the upper end during weight training from the standpoint of biomechanics through:

- Biomechanical analysis of the phenomenon of the second deficit. 
- Determine the percentage of disability of the upper limb during weight training.

Research Hypothesis:

1 - what is the mechanism of bilateral disability of the upper limb during weight training?

2- what is the ratio of bilateral disability of the upper end during weight training?

Research Terms:

1- Bilateral Deficit:

"It is the loss of power resulting from the performance of the two parties together (BL) than the sum of the forces produced at the performance of the unilateral parties." (14:9) Bilateral performance (BL):

"It is the work of both ends of the lower or upper part

Table (1)

together when performing muscle strength exercises." (14: 9)

Unilateral performance (UL):

"It is the work of each end of the lower or upper part alone when performing muscle strength exercises." (14: 9)

\section{Research Procedures:}

\section{1- Research Methodology}

The researcher used the descriptive method using the survey method to suit the nature of the study.

\section{2- Research Simple:}

The main study sample was chosen by deliberate method from the players participating in Maximum Gym Club in Port Said. The sample included (4) players.

\section{The Description of research sample $(n=5)$}

\begin{tabular}{|c|c|c|c|c|c|c|}
\hline & $\begin{array}{c}\text { Measurement } \\
\text { Unit }\end{array}$ & Mean & $\begin{array}{l}\text { Standard } \\
\text { deviation }\end{array}$ & $\begin{array}{c}\text { torsion } \\
\text { coefficient }\end{array}$ \\
\hline \multirow{4}{*}{$\begin{array}{l}\text { Growth } \\
\text { rates }\end{array}$} & 1 & $\overline{~ T a l l ~}$ & $\overline{\mathrm{Cm}}$ & 181.25 & 1.25 & 0.25 \\
\hline & 2 & Wight & $\mathrm{Kg}$ & 72.75 & 0.95 & 0.855 \\
\hline & 3 & Age & Year & 27.5 & 0.577 & 0.000 \\
\hline & 4 & training & month & 18 & 0.81 & 0.000 \\
\hline \multirow{2}{*}{$\begin{array}{l}\text { Arms } \\
\text { Force } \\
\text { test }\end{array}$} & 5 & $\begin{array}{l}\text { (Standing in front } \\
\text { of the muscular } \\
\text { strength device) } \\
\text { Bend your arms } \\
\text { high back toward } \\
\text { the body }\end{array}$ & $\mathrm{Kg}$ & 50.00 & 1.00 & 0.000 \\
\hline & 6 & $\begin{array}{l}\text { (Standing in front } \\
\text { of the muscular } \\
\text { strength device) } \\
\text { Bend one arm } \\
\text { upward toward the } \\
\text { body }\end{array}$ & $\mathrm{Kg}$ & 27.00 & 1.00 & 0.000 \\
\hline
\end{tabular}

From Table (1) it is clear that the values of the torsion coefficient for each of these variables (understudy) have been limited to $( \pm 3)$, which indicates the moderation of the iterative curve of the study sample in these variables.

\section{3- Data collection tools:}




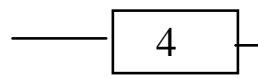

- Biomechanics Data collection tools:

Capture, 3D Video by Gopro hero4 black Camera (240fbs)

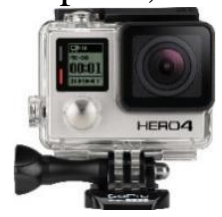

Figure (1) Gopro hero4 black

Calibration cube $2 * 2 * 1$

Table (2)

Dimensions of the calibration cube

\begin{tabular}{l|c|c}
\hline \hline & Camera 1 & Camera 2 \\
\hline \hline Camera distant from cube & $6.73 \mathrm{~m}$ & $6.73 \mathrm{~m}$ \\
\hline Camera height & $1.35 \mathrm{~m}$ & $1.35 \mathrm{~m}$ \\
\hline Distant between cameras & \multicolumn{2}{|c}{$4.15 \mathrm{~m}$} \\
\hline Camera`s angle & $90^{\circ}$ & $90^{\circ}$ \\
\hline \hline
\end{tabular}

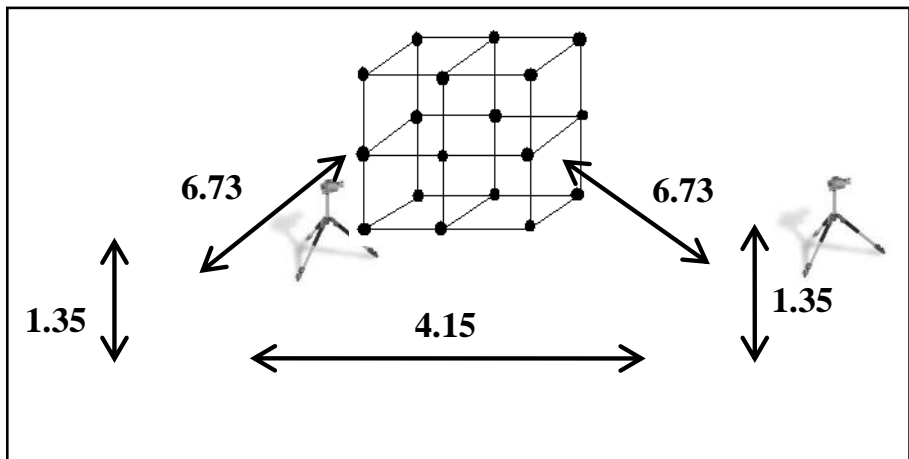

Figure (2) Dimensions of the calibration cube

- Biomechanics analysis by

"Kinonea" software:

Biokinematics analysis

system using real-time video

camera and computer by
Kinovea biomechanical analysis program, according to the proposed analysis model as shown in Figure (3)

Figure (3) analyzing the model

\begin{tabular}{||l|c|c|c|c|c|c|c||}
\hline \hline & \multicolumn{3}{|c|}{$\begin{array}{c}\text { Average body angles to measure bilateral disability } \\
\text { (bilateral muscular work) of the study sample }\end{array}$} & \multicolumn{3}{|c|}{$\begin{array}{c}\text { Mean body angles scores for measuring bilateral disability } \\
\text { (individual muscular work) of the study sample }\end{array}$} \\
\hline $\begin{array}{c}\text { Angle } \\
\text { of } \\
\text { Elbow }\end{array}$ & $\begin{array}{c}\text { Trunk tilt } \\
\text { angle } \\
\text { forward and } \\
\text { backward }\end{array}$ & $\begin{array}{c}\text { Trunk } \\
\text { tilt angle } \\
\text { of both } \\
\text { sides }\end{array}$ & $\begin{array}{c}\text { Angle } \\
\text { of Free } \\
\text { arm }\end{array}$ & $\begin{array}{c}\text { Angle } \\
\text { of } \\
\text { Elbow }\end{array}$ & $\begin{array}{c}\text { Trunk tilt } \\
\text { angle } \\
\text { forward } \\
\text { and } \\
\text { backward }\end{array}$ & $\begin{array}{c}\text { Trunk tilt } \\
\text { angle of both } \\
\text { sides }\end{array}$ \\
\hline \hline Phase & & & & &
\end{tabular}

Assiut Journal For Sport Science Arts 


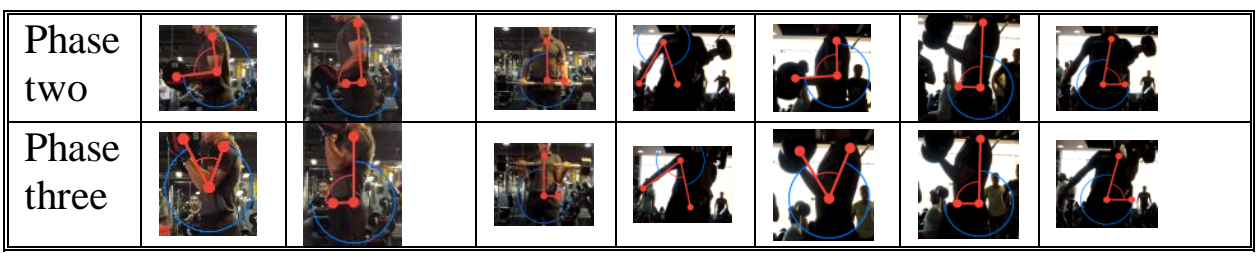

- Anthropometric Data collection tools

The methods and tools for data collection that are appropriate to the nature of the study were identified by looking at the scientific references, researches and previous studies.

- Restameter to measure the total length of the body.

- Medical balance device to measure the mass of the player.

4- Pilot Study:

The researcher conducted a pilot study to identify the conditions and problems that may face the researcher during the basic study and was implemented on Tuesday 23/7/2019, at Maximum Gym Club in Port Said. The survey was conducted on (1) players from one club. The survey aimed to identify:

- Dimensions for cameras.

- Visibility through cameras to facilitate later analysis.

And the pilot study achieved its objectives.

5- Basic study:

The basic study was carried out on Thursday 25/7/2019 at Maximum Gym Club in Port Said.

6- Statistical Treatments

The researcher used the program (Statistical Package for Social Science) (SPSS 20) (Statistical Package for Social Science) in the processing of data statistically using the appropriate statistical coefficients of the study.

\section{7- Results:}

1- Present the results:

This chapter includes the presentation and discussion of the results by studying the differences in the results of biomechanical analysis, in the light of the data and results of the measurements under study on the sample and based on the results of statistical analysis that are consistent with the nature of the current study. In the light of the study hypotheses, the researcher will present his findings as follows:

- Presentation of the data of the biomechanical variables under study:

- Degrees of body angles of angles under study and backward to measure bilateral disability (bilateral muscular work - individual muscular work) of the study sample:

Table (3)

Body angles scores the body angle under study to measure bilateral deficits (bilateral muscle work - individual muscle work) of the study sample 


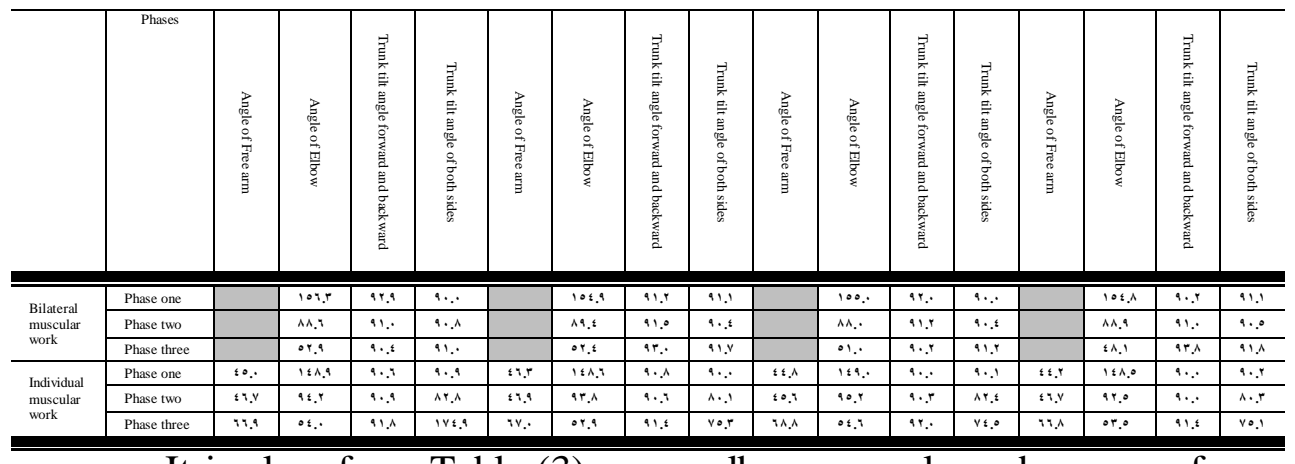

It is clear from Table (3) the angles of the body under study, where it is clear that the degrees of tilt angle of the sides of the work of the individual and bilateral muscle ranged between (91.8 - 74.5) during the three phases of performance, and the degrees of tilt angle of the front and back of the work of the individual muscle and bilateral ranged between (93.8 During the three performance phases, elbow angle degrees for individual and bilateral muscular work ranged from 165.3- 148.6 during the first phase, 95.2- 88.0 during the second phase, and 54.6- 48.1 during the third phase. The degrees of free arm angle for individual muscular work ranged between (44.2- 46.3) during the first phase, and (45.6) - 46.9) during the second phase, $(68.8$ - 66.8) during the third phase.

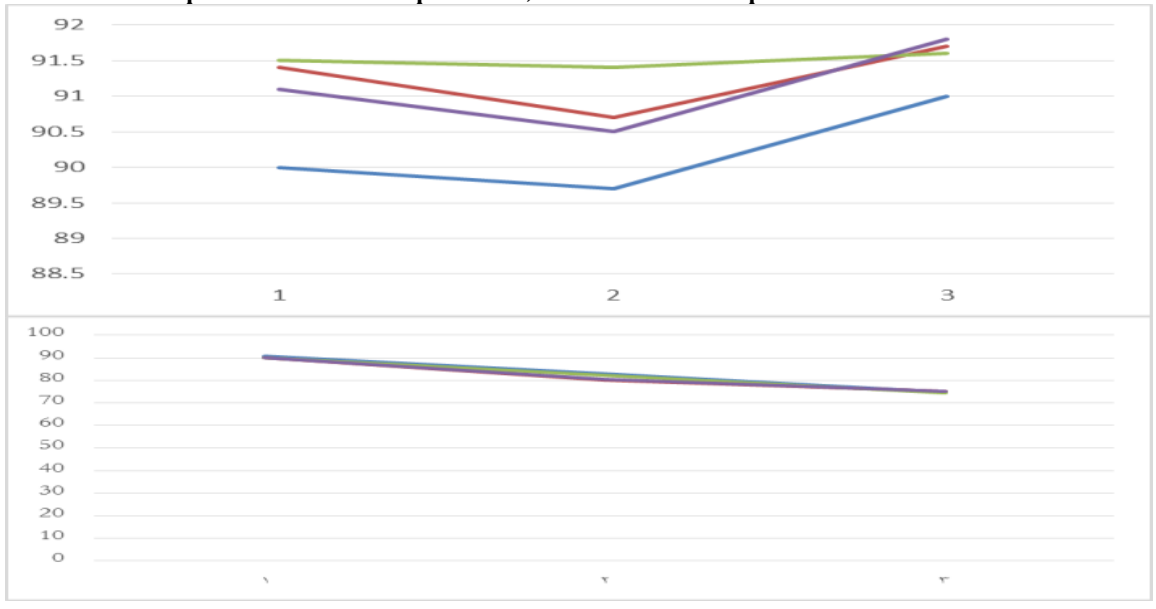

Assiut Journal For Sport Science Arts 


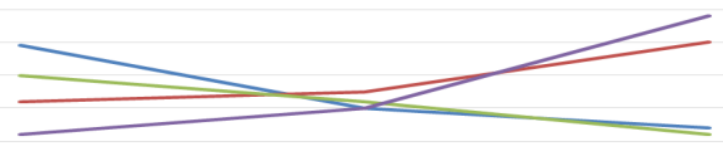

Figure (6) Trunk tilt angle forward and backward (Bilateral muscular action)

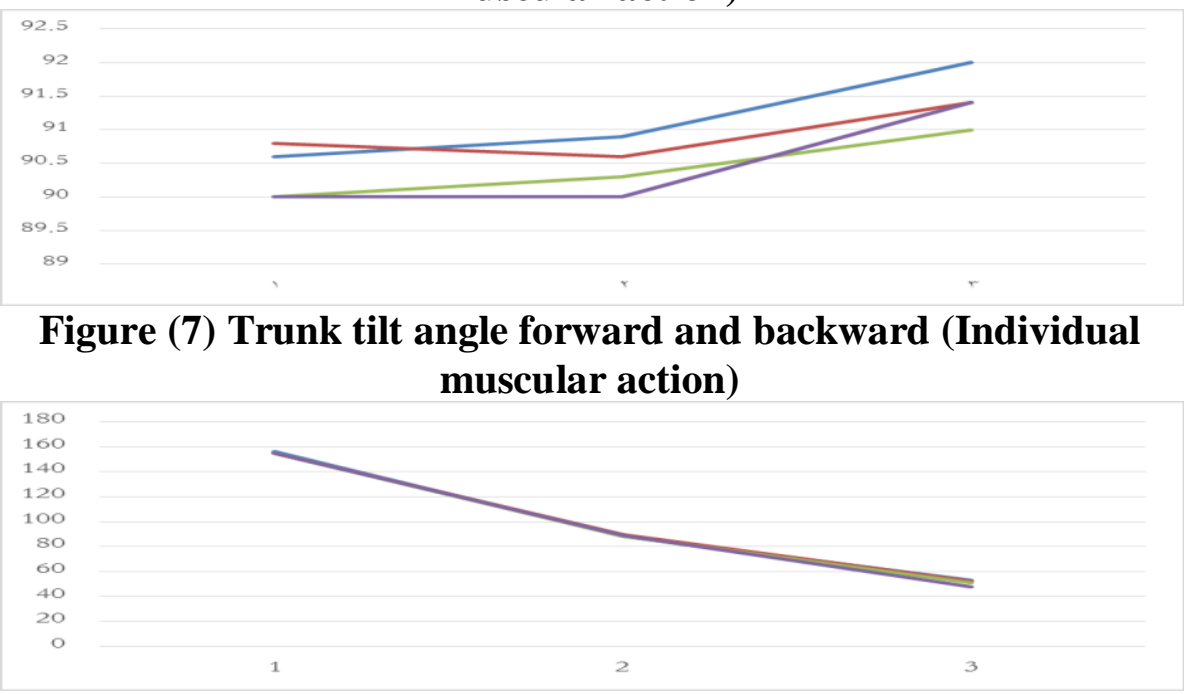

Figure (8) Angle of Elbow (Bilateral muscular action)

80
70
60
50
40
30
20
10
0

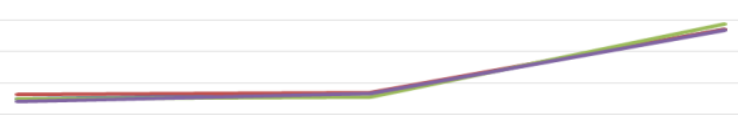

Figure (9) Angle of Elbow (Individual muscular action)

80
70
60
50
40
30
20
10
0

Figure (10) Angle of Free arm (Individual muscular action)

Assiut Journal For Sport Science Arts 
Average degrees of body angles:

Table (4)

Average degrees of body angles

\begin{tabular}{|c|c|c|c|c|c|c|c|}
\hline & \multicolumn{4}{|c|}{$\begin{array}{l}\text { Average angles of the body } \\
\text { (individual muscle action) }\end{array}$} & \multicolumn{3}{|c|}{$\begin{array}{c}\text { Average body angles } \\
\text { (bilateral muscle action) }\end{array}$} \\
\hline & $\begin{array}{c}\text { Angle of } \\
\text { Free } \\
\text { arm }\end{array}$ & $\begin{array}{c}\text { Angle } \\
\text { of } \\
\text { Elbow }\end{array}$ & $\begin{array}{c}\text { Trunk tilt angle } \\
\text { forward and } \\
\text { backward }\end{array}$ & $\begin{array}{c}\text { Trunk tilt } \\
\text { angle of } \\
\text { both sides }\end{array}$ & $\begin{array}{l}\text { Angle of } \\
\text { Elbow }\end{array}$ & $\begin{array}{c}\text { Trunk tilt angle } \\
\text { forward and } \\
\text { backward }\end{array}$ & $\begin{array}{c}\text { Trunk tilt } \\
\text { angle of } \\
\text { both sides }\end{array}$ \\
\hline Phase one & $\varepsilon 0 . V$ & $1 \leqslant \Lambda . \cdot V$ & $9 . .10$ & $9 \cdot . r$ & 100.10 & $91.0 \mathrm{~V}$ & $9 . .00$ \\
\hline Phase two & $\leqslant 7 . \leqslant V$ & 94.94 & $9 \cdot . \leq 0$ & $\lambda I . \varepsilon$ & $\wedge \wedge . \vee Y$ & $91.1 \mathrm{~V}$ & $9 . .0 Y$ \\
\hline Phase three & TV.rV & or.vo & 91.70 & $V \leqslant .90$ & 01.1 & 91.10 & $91 . \leqslant Y$ \\
\hline
\end{tabular}

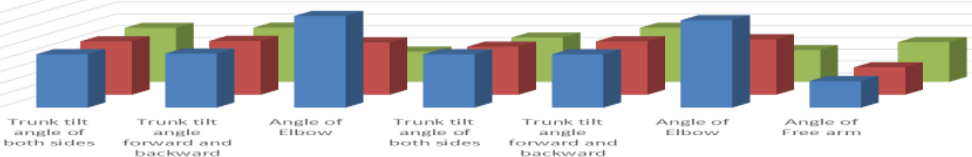

Figure (11). Average degrees of body angles

3- Significance of differences between the two measurements of angles under study to measure bilateral disability (bilateral muscular work - individual muscular work)

Table (5)

Wilcoxon Indication of differences between the two measurements of the angle of inclination of the trunk forward and backward (bilateral muscle work - individual muscle work)

\begin{tabular}{l|l|c|c|c|c|c|c}
\hline \hline & \multirow{2}{*}{ Phases } & $\begin{array}{c}\text { Mean } \\
\text { Rank }\end{array}$ & $\begin{array}{c}\text { Sum of } \\
\text { rank }\end{array}$ & $\begin{array}{c}\text { Mean } \\
\text { Rank }\end{array}$ & $\begin{array}{c}\text { Sum of } \\
\text { rank }\end{array}$ & \multirow{z}{*}{ Significance } \\
\cline { 3 - 7 } & & - & + & - & + & & \\
\hline \hline 1 & Phase one & 0.00 & 2.50 & 0.00 & 10.0 & -0.826 & 0.068 \\
\hline 2 & Phase two & 1.00 & 3.00 & 1.00 & 9.00 & -1.461 & 0.144 \\
\hline 3 & Phase three & 1.75 & 3.25 & 3.50 & 6.50 & 0.552 & 0.581 \\
\hline \hline
\end{tabular}

Table (6)

Wilcoxon Indication of differences between the two measurements of the angle of Trunk tilt angle of both sides (bilateral muscle work individual muscle work)

\begin{tabular}{l|l|c|c|c|c|c|c}
\hline \hline & \multirow{2}{*}{ Phases } & $\begin{array}{c}\text { Mean } \\
\text { Rank }\end{array}$ & $\begin{array}{c}\text { Sum of } \\
\text { rank }\end{array}$ & $\begin{array}{c}\text { Mean } \\
\text { Rank }\end{array}$ & $\begin{array}{c}\text { Sum of } \\
\text { rank }\end{array}$ & \multirow{2}{*}{$z$} & \multirow{2}{*}{ Significance } \\
\cline { 3 - 7 } & - & + & - & + & & \\
\hline \hline 1 & Phase one & 1.50 & 2.93 & 1.50 & 8.50 & -1.300 & 0.194 \\
\hline 2 & Phase two & 0.00 & 2.50 & 0.00 & 10.0 & -2.121 & $0.043^{*}$ \\
\hline 3 & Phase three & 0.00 & 2.50 & 0.00 & 10.0 & -2.121 & $0.043^{*}$ \\
\hline \hline
\end{tabular}

Means the presence of statistically significant differences at the level of significance (0.05)

Assiut Journal For Sport Science Arts 


\section{Table (7)}

Wilcoxon Indication of differences between the two measurements of Angle of Elbow (bilateral muscle work - individual muscle work)

\begin{tabular}{l|l|c|c|c|c|c|c}
\hline \hline & \multirow{2}{*}{ Phases } & $\begin{array}{c}\text { Mean } \\
\text { Rank }\end{array}$ & $\begin{array}{c}\text { Sum of } \\
\text { rank }\end{array}$ & $\begin{array}{c}\text { Mean } \\
\text { Rank }\end{array}$ & $\begin{array}{c}\text { Sum of } \\
\text { rank }\end{array}$ & \multirow{2}{*}{$\mathbf{Z}$} & \multirow{2}{*}{ Significance } \\
\cline { 3 - 6 } & - & + & - & + & & \\
\hline \hline 1 & Phase one & 0.00 & 0.50 & 0.00 & 10.0 & -1.841 & 0.6 \\
\hline 2 & Phase two & 2.50 & 0.00 & 10.0 & 0.00 & -1.841 & 0.66 \\
\hline 3 & Phase three & 2.50 & 0.00 & 0.0 & 0.00 & -1.826 & 0.68 \\
\hline \hline
\end{tabular}

- Percentage of bilateral disability (bilateral muscular work individual muscular work) of the study sample:

The amount of bilateral deficit is calculated by the following equation: $B L D(\%)=\left(100 \times \frac{\text { bilateral performance }}{\text { right unilateral }+ \text { left unilateral }}\right)-100$

\section{Table (8)}

Percentage of bilateral disability (bilateral muscular work individual muscular work) of the study sample

\begin{tabular}{c|c|c|c|c|c}
\hline \hline & & $\begin{array}{c}\text { Maximum strength } \\
\text { of bilateral } \\
\text { muscular action }\end{array}$ & $\begin{array}{c}\text { Maximum strength } \\
\text { of individual } \\
\text { muscular work }\end{array}$ & $\begin{array}{c}\text { The difference } \\
\text { between the } \\
\text { maximum strength }\end{array}$ & $\begin{array}{c}\text { Bilateral } \\
\text { Percentage }\end{array}$ \\
\hline \hline 1 & Player 1 & 50 & 54 & 4 & \\
\hline 2 & Player 2 & 50 & 54 & 4 & \\
\hline 3 & Player 3 & 50 & 54 & 4 & \\
\hline 4 & Player 4 & 50 & 54 & 4 & $8 \%$ \\
\hline \multicolumn{7}{r|}{ Mean } & 50 & 54 & 4 & $8 \%$ \\
\hline \hline
\end{tabular}
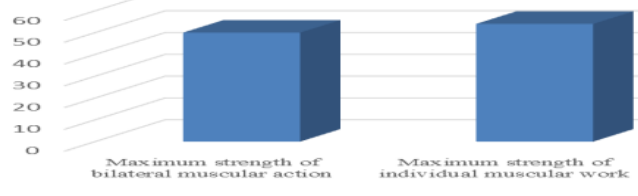

The dirmeremce between
the maximum strengeth

\section{Figure (12). Percentage of bilateral}

Discussion of the results:

Discussion of the results of the first Question:

"What is the mechanism of bilateral disability in the upper limb during weight training?"

It is clear from Table (5) that there are no statistically significant differences between the angles of the tilt of the trunk forward and backward between bilateral muscle work and individual muscle work.

Table (4) shows that the average inclination angle of the trunk forward and backward during bilateral muscle work in the first phase $91.75^{\circ}$ and in 
the second phase $91.17^{\circ}$ and in the third phase $91.85^{\circ}$, while the average angle of inclination of the trunk forward and backward during the individual muscle work in the first phase $90.35^{\circ}$ in the second phase $90.45^{\circ}$ and in the third phase $91.65^{\circ}$

The researcher attributes this to the player's tightening of the muscles of the back, abdomen, shoulder and chest belt, which reduces the tendency of the trunk forward or back in an attempt to overcome the resistance encountered during lifting the weight, whether with arms or one arm, which leads to not tilt the trunk forward or back in all From individual and bilateral muscular work, consistent with Otoski (1981) (19), Vanderfort et al. (1984) (23).

As shown in Table (7), there are no statistically significant differences between the angles of the elbow during the individual muscular work and the individual muscular work, as Table (4) shows that the average angle of inclination of the elbow during the bilateral muscular work in the first phase $155.25^{\circ}$ and in the second phase In phase III $51.1^{\circ}$, the average inclination angle of the elbow during individual muscular work in phase I was $148.07^{\circ}$, in phase II $93.92^{\circ}$ and in phase III $53.75^{\circ}$.

The researcher attributes this to the fact that the player seeks the maximum contractility of the muscular biceps Muscle Biceps Muscle, which is consistent with both Mohammed Al-Angari, Mohammed Deif (2016) (1), and Hani Abdul Aziz (2019 AD) (7) that the elbow joint has only two degrees of freedom DOF namely Tide and flexion is also considered to be a joint and characterized by the movement of large movement with reduced amount of loss of force during the movement of the joint.

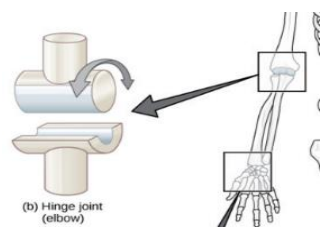

\section{Figure (13) Elbow joint}

The test used to measure the bilateral disability of the upper limb during weight training requires the player to reach the maximum muscle contractility of the joint, and was excluded attempts that did not reach the elbow joint to the maximum extent.
Consistent with Vander Fort et al. (1987) (24), Carnell Andrew et al. (2012) (3), and Jacob Scarabout et al. (2016) (10) in that it is a condition of measuring bilateral disability and the joint's arrival of its maximum contraction.

The researcher attributes this to the fact that the length 
of the arc that moves the gravity is almost equal in both bilateral muscle work and

\section{Table (9)}

Percentage of bilateral disability (bilateral muscular work individual muscular work)

\begin{tabular}{l|l|l|l|c|c|c|c|c}
\hline \hline & \multirow{2}{*}{$\begin{array}{l}\text { Body } \\
\text { Length }\end{array}$} & $\begin{array}{l}\text { Upper } \\
\text { Arm } \\
\end{array}$ & Length & \multicolumn{2}{|c|}{ Angle Degree } & \multicolumn{2}{c|}{ Radian } & \multicolumn{2}{c}{ Bow length } \\
\cline { 5 - 9 } & Bilateral & Individual & Bilateral & Individual & Bilateral & Individual \\
\hline \hline \multirow{2}{*}{ Player 1 } & 180 & 28.26 & 106.7 & 95 & 1.862 & 1.658 & 52.63 & 46.86 \\
\hline Player 2 & 181 & 28.41 & 104 & 94.4 & 1.815 & 1.647 & 51.58 & 46.82 \\
\hline Player 3 & 182 & 28.57 & 102.4 & 95.7 & 1.670 & 1.670 & 51.07 & 47.73 \\
\hline Player 4 & 182 & 28.57 & 103.4 & 94.9 & 1.656 & 1.656 & 51.57 & 47.33 \\
\hline Mean & 181.25 & 28.4 & 104.12 & 95 & 1.658 & 1.658 & 51.71 & 47.18 \\
\hline \hline
\end{tabular}

As shown in Table 9, the average length of the arc in bilateral muscular work was $51.71 \mathrm{~cm}$ and in individual muscular work was $47.18 \mathrm{~cm}$, which caused no differences in the angle of the elbow joint during the measurement of bilateral deficits under study, consistent with Howard et al. (1991) (9), Gordon et al. (2004) (4) that angular muscular work is highly correlated with the length of the arc that the body travels where it is the work piece of performance.

As shown in Table (6), there are no statistically significant differences between the tilt angles of the torso forward and backward between individual muscle work and individual muscle work during the first stage of performance.

Table (4) shows that the average inclination angle of the torso for both sides during bilateral muscular work in the first stage is $90.55^{\circ}$, while the average inclination angle of the sides during the individual muscular work in the first stage is $90.30^{\circ}$. individual muscle work as shown in Table (9).
The researcher attributes this to the fact that the starting position in both individual muscle work and bilateral muscle work is similar, there is no difference or mechanical differences in the starting position during this stage, which is proved by the results of Table (4).

As shown in Table (4) there is a relative stability in the angle of inclination of the trunk of the sides during bilateral muscular work, where in the first stage $90.55^{\circ}$ and in the second stage $90.52^{\circ}$ and in the third stage $91.42^{\circ}$.

The researcher attributed this to the fact that the distribution of weight evenly on both ends of the body led to the balance of the body during the performance and stability of the body shape, which is consistent with Abdulrahman Al-Angari and Mohammed Deif (2016) (1), and Matukoski et al. (2011) (15) to be equivalent to external forces acting On the body lead to the balance of the body and gain motor stability.

there As shown in Tatistically 
significant differences between the angle of the torso tilt for both sides to measure bilateral disability during individual muscle work in the second and third stages of performance, where Table (4) shows that the average angle of tilt of the sides during the individual muscle work in the second stage $93.9^{\circ}$ and in the second stage $53.75^{\circ}$.

The researcher attributes the different angles due to the inclination of the trunk towards the working arm, as an automatic reaction to engage the chest and shoulder muscles in the muscular work in order to overcome the resistance of gravity.

This is consistent with Henry Smith et al. (1961) (8) and Hackenen et al. (1995) (6) that the muscles involved in weight lifting are directly related to the motor nerves responsible for them, and that the muscle reaction is a way to overcome Resistance to muscle.

This is also consistent with Usha Kuru Ganti (2011) (21) and Hani Abdulaziz (2019) (7) in that the muscle contraction starts from the arrival of the neuronal signal through the motor unit, which is directly related to the brain and thus the neurological reactions resulting from the brain.

This gives preference to individual muscular work, which is consistent with Moorhouse et al. (2000), (17) and Ouda et al. (1994) (18). The attention of the player and the dispersion of nerve signals during bilateral muscular work. As shown in Table (4), the angle of the free arm during the individual muscular work gradually increases in the stages of performance, reaching the average angle of inclination of the free arm during the individual muscular work in the first stage $45.07^{\circ}$, the second stage $46.47^{\circ}$, and in the second stage $76.37^{\circ}$. It is also evident that there is no free arm during bilateral muscle work, because both arms are involved in overcoming gravity.

The researcher believes that this is a major factor in the existence of the phenomenon of bilateral disability, since the free arm is considered in this case as a mechanical tool that works to help the player's body to overcome the resistance it faces on the other arm.

It is clear from Table (9) that the length of the bow that the lever arm crossed was about $47.18 \mathrm{~m}$ in individual muscular work, whereas in bilateral muscular work was $51.71 \mathrm{~cm}$. Reduce the arc that cuts the weight and thus the ability of the muscle to exert greater strength during individual muscle performance.

The length of the arc and the multiplication of the force exerted in order to calculate the work done shows that the work done during the individual muscle work is less than in the work of the bilateral muscle work, which in turn gives preference to the work of the individual muscle work. 
Discussion of the results of the second Question:

"What is the ratio of the upper limb bilateral disability during weight training?"

As shown in Table (8), the ratio of bilateral disability to $(8 \%)$ of the total muscle strength exerted, as the average maximum strength of the upper limb during bilateral muscle work $(50 \mathrm{~kg})$, while the maximum strength of the upper limb of individual muscle work $(27 \mathrm{~kg})(54 \mathrm{~kg})$ for the arms.

Bilateral deficits were between $6 \%$ and $18 \%$ in many studies, consistent with the results of each Kwakami study (1998) (12), Jacob Shelbeck (2001) (11), Kudogian et al (2003) (13), Zigdwing (2007) (25), and Jacoby et al. (2016) (10).

\section{Conclusions}

and

recommendations:

\section{Conclusions:}

Based on the results of the research and in the light of the objective and hypotheses of the research, the researchers reached the following conclusions:

- Determine the percentage of bilateral disability of the muscular work of the upper limb by about ( $8 \%)$.

- the angle of inclination of the trunk of both sides is a major factor in the phenomenon of bilateral disability.

- The angle of the free arm is a major factor in the phenomenon of bilateral disability.

- Both the free arm and the torso inclination of both sides are factors that give preference to individual muscular work.

- the greater the length of the bow that the arm cuts during muscle work, which leads to the emergence of bilateral disability.

\section{recommendations}

Based on the Conclusions of the research and the conclusions reached, the researchers recommend the following:

- Study of the phenomenon of bilateral disability of the lower limb.

- Observe the tilt angle of the torso during training to overcome the phenomenon of bilateral disability.

- Observe the angle of free arm inclination during training to overcome the phenomenon of bilateral disability.

- Work to increase the length of the arch and increase the angle of muscle work during training the upper limb to overcome the phenomenon of bilateral disability.

- Use the equation

$$
B L D(\%)=\left(100 \times \frac{\text { bilateral performance }}{\text { right unilateral +left unilateral }}\right)-
$$

\section{0}

" to calculate the phenomenon of bilateral disability.

\section{References:}

\section{1- Abdul Rahman Al}

\section{Anqary, Mohamed deef:}

\section{Assiut Journal For Sport Science Arts}


(2016): Sports biomechanics physical activities, saud Uni. Publisher, Saudi Arabia.

2- Adel \& Ehab Abdel Baser. (2005):

Biomechanical analysis theory and application in spoerts, $\mathrm{Al}$ Motahedah Publication, Port Said.

3- Cornwell, Andrew \& Khodiguian, Nazareth \& Yoo, Eun. (2012): Relevance of hand dominance to the bilateral deficit phenomenon. European journal of applied physiology. 112. 10.1007/ s00421-012-2403-z.

4- D,Gordon E,Rbertson, Gary kamen, Graham E, Caldwell, Joseph Hamil, Saunders- N, Whittlesey: (2004): Research Methods in Biomechanics, Human Kinetics publisher ; Champaign.

5- Essam helmy, Gaber bureqaa: (1997): Sports Training, Dar Al Fekr Al Araby, Egypt.

8- Ha kkinen $K$, Pastinen UM, Karsikas R, Linnamo V (1995) Neuromuscular performance in voluntary bilateral and unilateral contraction and during electrical stimulation in men at different ages. Eur J Appl Physiol 70:518-527

9- Hani Abdul Aziz Saleh: (2019): Principles of Kinesiology, Al-Mutanabbi Publishing and Distribution House, Dammam, Saudi Arabia.

10- Henry FM, Smith LE (1961): Simultaneous vs. separate bilateral muscular contractions in relation to neural overflow theory and neuromata specificity. Res Q Exerc Sport 32:42-46 11- Howard J, Enoka R: (1991) Maximum bilateral contractions are modified by neurally mediated interlimb effects. J Appl Physiol 70:306316.

12- Jakob Škarabot, Neil Cronin, Vojko Strojnik \& Janne Avela: (2016): Bilateral deficit in maximal force production, Arbeits physiologie 13- Jakobi JM, Chilibeck PD (2001): Bilateral and unilateral contractions: possible

differences in maximal voluntary force. Can J Appl Physiol 26:12-33

14- Kawakami Y, Sale DG, MacDougall JD, Moroz JS (1998): Bilateral deficit in plantar flexion: relation to knee joint position, muscle activation, and reflex excitability. Eur J Appl Physiol 77:212-216

15- Khodiguian N, Cornwell A, Lares E, DiCaprio PA, Hawkins SA (2003)

Expression of the bilateral deficit during reflexively evoked contractions. J Appl Physiol 94:171-178

16- Mahmoud Qasim: (2009), "the impact of various resistance exercises to alleviate bilateral disability and some physical, motor and skill capabilities of volleyball players," Unpublished Master Thesis, College of Basic Education - University of Mustansiriya, Baghdad.

17- Matkowski B, Martin A, Lepers R (2011): Comparison of maximal unilateral versus bilateral voluntary contraction 
force. Eur J ApplPhysiol 111(8):1571-1578

18- Mohamed Moneer: (2003), Effect of some of the methods of "lengthening shortening" on the muscle capacity of the two men for volleyball players ", Master Thesis, unpublished, Faculty of Physical Education, Banha Branch, Zagazig University 19- Morehouse SA, Szeligo F, DiTommaso E (2000) Characteristics of the bimanual deficit using grip strength. Laterality 5(2):167-185

20- Oda S, Moritani T (1994) Maximal isometric force and neural activity during bilateral and unilateral elbow flexion in humans. Eur J Appl Physiol 69:240-243

21- Ohtsuki T (1981): Decrease in grip strength induced by simultaneous bilateral exertion with reference to finger strength. Ergonomics 24:37-48

22- Rejc E, Lazzer S, Antonutto G, Isola M, di Prampero PE (2010) Bilateral deficit and EMG activity during explosive lower limb contractions against different overloads. Eur J Appl Physiol 108(1):157-165
23-Usha Kuruganti, Tiernan Murphy, Trevor Pardy: (2011): Bilateral deficit phenomenon and the role of antagonist muscle activity during maximal isometric knee extensions in young, athletic men, European Journal of Applied Physiology, Volume 111 ,

24- Van Diee"n JH, Ogita F, De Haan A (2003): Reduced Neural drive in bilateral exertions: a performance limiting factor? Med Sci Sports Exerc 35(1):111-118

1- Vandervoort AA, Sale DG, Moroz JR (1984) Comparison of motor unit activation during unilateral and bilateral leg extension. J Appl Physiol 56:46-51.

25- Vandervoort AA, Sale DG, Moroz JR (1987): Strength-velocity relationship and fatigability of unilateral versus bilateral arm extension. Eur J Appl Physiol 56:201-205 26- Zijdewind I (2007) Reduced cortical activity during maximal bilateral contractions of the index finger. Neuroimage 35(1):1627 